\title{
Role of Financial Institutions in the Growth of Micro and Small Enterprises in Dire Dawa Administration
}

\author{
Abel Zegeye W/Gebriel \\ Department of Business and Accounting, Ethio-Italy Polytechnic College \\ Dire Dawa Administration, Ethiopia
}

\begin{abstract}
The target of this study was to research the role of financial institutions on the growth of micro and small enterprises in Dire Dawa Administration. the specific objectives of this study were; to determine the role of financial institutions, MFIs' saving services on the growth of MSE in Dire Dawa Administration, to determine the role of monetary institutions, MFIs' loan services on the growth of MSE in Dire Dawa Administration and to research the role of financial institutions, MFIs' training services on the expansion of MSE in Dire Dawa Administration. These objectives sought to answer the subsequent questions: what is the role of financial institutions, MFIs' saving services on the growth of MSE in Dire Dawa Administration? What is the role of financial institutions; MFIs' loan services on the growth of MSE in Dire Dawa Administration? And, what's the role of financial institutions, MFIs' training services on the growth of MSE in Dire Dawa Administration? The study adopted descriptive research design targeting a sample size of 245 MSE. Primary data was collected using structure questionnaires while secondary data was collected from relevant literature. The study used selfadministered questionnaires to gather primary data from the respondents. Quantitative data was analyzed using descriptive statistics like frequencies, modes, means and standard deviations. Likert type data was analyzed using mode because the focus of discussion. Correlation and regression was conducted to work out the role of monetary institutions, MFIs' on the expansion of MSE within the study area. The study findings revealed financial institutions; MFIs' saving and loan services have positively and significantly influenced the growth of MSE in Dire Dawa Administration but the training services have not contributed positively. The study recommends there is need for MFIs and MSE stakeholders to return up with measures of addressing the poor performing training component of MFIs services in Dire Dawa Administration, Ethiopia.
\end{abstract}

Keywords: Role, Micro Financial Institution, Micro and Small Enterprise, Growth

DOI: $10.7176 / \mathrm{EJBM} / 13-5-05$

Publication date:March $31^{\text {st }} 2021$

\section{Introduction}

Micro and Small Enterprises (MSE) and microfinance institutions are the main actors and contributors to the performance of an economy. MSE play a crucial role in developing the economy and in creating employment. They are providing employment, income opportunities to people. Moreover they are at the forefront of technological innovations and export diversification. Similarly, financial institutions play a crucial role in firms' growth. According to ((Wolday, 2000) as cited in Gelfeto Gelassa Titta \& Dr.Aravind Soudikar, 2015) they provide suitable financial and other services at low cost to meet the need of low income sections of the people and act as a sound medium of exchange and facilitate trading. Furthermore, they provide financial assistance to satisfy the various needs of enterprises. Zeller (2003) as cited in (Nigussie, 2012) broadly defined financial institution as an organization, which may be either for-profit or nonprofit, that takes money from clients and places it in any of a selection of investment vehicles for the advantage of both the client and thus the organization. Common samples of monetary institutions are banks, insurance companies, credit Associations, microfinance, financial and economic firms.

The term MSE covers an honest range of definitions and measures, varying from country to country and between the sources reporting MSE statistics. Although there is no universally agreed definition of MSE variety of the commonly used criteria are the quantity of employees, value of assets, value of the sale and size of capital or turnover. However, the foremost common basis of defining MSE is number of employees (Nugent, 2001) as cited in (Nigussie, 2012). Whatever the definition, and regardless of the size of the economy, the expansion of MSE is increasingly crucial to economic development. The problem of MSE development ranks high among the priorities of socio-economic development, given the growing need for employment creation and poverty alleviation (Abdulmelike, Bese (phd), \& Sime, 2018). As Nugent (2001) as cited in (Nigussie, 2012) further noted that there is also an urgent need to create a strong competitive MSE sector that is able to play variety role within the growth process.

Since MSE' sector does have a very significant role within the Ethiopian economy, the government was striving to form competitive and productive MSE sector. It is for this reason that the Ethiopian government develops policy so on address the constraints and to tap the entire potential of the industry. This policy are going to be function guidelines to all or any stakeholders and thus motivate new enterprises to be formed and existing 
ones to expand and become more competitive. When MSE start a business, they need startup capital or existing MSE are growing rapidly its current financial resources could even be inadequate. Most new or growing MSE are not able to finance their startup or expansion plans from income alone. It therefore needs to consider raising finance from other external sources. In support of this, the Ethiopia government to offer adequate supply of monetary services to varied sectors of the economy, especially to MSE, has evolved an honest kind of financial institutions both at the national and regional level as a means of fighting poverty and income inequality. Therefore, it is absolutely essential that the financial institutions should contribute for the growth of MSE not only quickly but also at a minimal cost. In handling the growth of MSE, financial institutions are one essential organ because a critical element for the growth of MSE is access to financial services and institutions. However, there appears to be limited evidence that confirms the contribution of finance institutions for MSE growth. There, the examination of microfinance institutions role in SMEs growth in Ethiopia, particularly in Dire Dawa Administration is the main focus of the study.

\section{Statement of the Problem}

The study was targeted on the Micro and Small Enterprises growth, which play crucial role on the economic expansion of country and were base of industries particularly and microfinance institutions' role generally. Famously, Micro and Small Enterprises are a basic issue, which are the sources of job possibility for worker and great proportion income generation for society. Studies conclude that the support of MSE during this context have long been acknowledged everywhere the world (Carl Liedholm, 2001); (ILO, 2003); (mdar, D., and A. Mazaheri , 2003).

Although, MSE great contribution in countries enhancement and economic development, their enlargement and progress in emerging countries were mainly influenced by right to use of finance, poor decision-making ability, and lack of coaching opportunities and increasing price of inputs (Cook, P. and F. Nixon, 2000). Supplementary studies executed recommend that finance is that the most imperative requirement for the MSE sector (Green et al, 2002). The MSE have extremely narrow right to use financial services from formal financial institutions with jointly their operational and investment desires (Kessy, S. \& Temu, S.S., 2010).

People have not any access to urge credit or money for self-employment and lack of access to support are the main problems that prevail within the urban areas of the developing countries. Because of this MSE cannot take credit from financial sectors like banks. This pushes them to borrow money from urban money lenders at exorbitant interest rates. All the above problems are manifestations of poverty within the developing countries including Ethiopia. Concerning these problems, various approaches and lots of innovative institutional mechanisms are developed across the planet in reducing poverty by providing credit and related services to reinforce the access of household to financial service to poor (Gelfeto Gelassa Titta, Dr B. V., , \& Prasada Rao, 2013).

Therefore, it is absolutely essential that the financial institutions should contribute for the growth of MSE not only quickly but also at a minimal cost. However, as shown within the literature review, there appears to be limited evidence that confirms the contribution of microfinance institutions for MSE growth in Dire Dawa Administration context. Therefore, the deficiencies of the previous studies alongside the above discussed issues involved the present research.

\section{Literature Review}

\subsection{Microfinance Institution}

As mentioned by (Robinson, M., 2003) definition: 'Microfinance' refers to small-scale financial servicesprimarily credit and savings-given to people; who add microenterprises or small enterprises. Microfinance features a vital role to play in development consistent with proponents of microfinance. (United Nations Capital Development Fund (UNCDF), 2004) States that study have shown that microfinance plays three key roles in growth of micro and small enterprises.

1) It helps very poor society meet basic needs and protects against risks.

2) It is related to improvements in household economic welfare.

3) It helps to empower women by supporting women's economic participation then promotes gender equity.

\subsection{Micro and Small Enterprises (MSEs)}

According to the MSEs development strategy in Ethiopia (MSE Strategy, 2011), enterprises are categorized by capital and human power as follow: 
Table 1 Meaning of MSEs according to Ethiopian Trade and Industry Office

\begin{tabular}{|l|r|r|r|}
\hline \multicolumn{1}{|c|}{ Enterprise } & Sector & \multicolumn{1}{c|}{ Capital } & Human Power \\
\hline \multirow{2}{*}{ Micro } & Industry & $\leq 100,000$ birr & $\leq 5$ \\
\cline { 2 - 4 } & Service & $\leq 50,000$ birr & $\leq 5$ \\
\hline \multirow{2}{*}{ Small } & Industry & $\leq$ birr 1.5 million & $6-30$ \\
\cline { 2 - 4 } & Service & $\leq$ birr 500,000 & $6-30$ \\
\hline
\end{tabular}

Source: (MSE Strategy, 2011)

\subsection{Growth of Micro and Small Enterprises}

Hoy et al. (1992) stress that a consensus has been reached among academics that sales growth is that the best growth measure. There is to some extent an inverse relationship between capital investment and employment growth, as a consequence, assets are another important measure of growth. Measuring growth in terms of assets is usually considered problematic within the service sector (Weinzimmer, 1998).

\subsection{Microfinance Services and Growth of Micro and Small Enterprises}

\subsubsection{Loan Service}

Micro financing or access to credit are often defined as giving small amounts of cash in sort of loans (microloans) to micro and little scale borrowers who in a method or another lacks collateral or security, employment or/and a verifiable credit history. A crucial factor that considered resulting in improved growth, development and general growth of MSEs is access to credit. Credit leads to increased income and employment thereby alleviate poverty. Through access to credit poor people are ready to undertake investments and overcome their liquidity constraints. Improvement of farm technology, for example, results in increased agricultural production (Heidhues, 1995). The key outcome of microfinance is to complement the welfare of the poor through provision of micro-loans that the formal financial institutions do not offer (Navajas, S., Schreiner, M., Meyer, R.L , Gonzalez-Vega, C., \& Rodrigez-Mesa, J., 2000). For the poor just round the poverty level, inadequate access to credit finance may cause adverse consequences for the MSEs and on the general welfare of the poor (Diagne, A. \& M. Zeller, 2001). With access to credit MSEs can further increase their abilities on riskbearing, improve strategies of copying with risk and enable smoothing of consumption overtime. Considering these arguments, it is clear that micro financing services improve the wellbeing and welfare of the poor.

H1: Loan Service has significant and positive effect on micro and small enterprises growth.

3.3.2 Saving Service

Saving Service: Saving is not only important to non-public persons but it is also equally important for fulfillment and growth of any business. While the business is making profit, the business owner should explore starting a savings plan which may provide relief during tough times also as for funding investments. A study by (Zeller, M., 1993) shows that for purposes of smoothing household consumption, liquid savings are better as compared to other savings techniques. Savings are often withdrawn and utilized in times of emergency also on cover healthcare. The expansions of the household economic asset portfolio are often realized through the utilization of savings accounts. Mobilization of savings provides a way of funding investments. Capability to deposit and withdraw funds from a bank reduces the necessity to use inconvenient techniques of savings. Whereas it is common to withdraw cash from a business, the practice is not an honest means of funding household expenses or unanticipated business expenses. A bank account has the potential of enhancing the power to plan and canopy such expenses. The rapid evolution of microfinance, with specialization in lending small sums, is partly the rationale why the poor can borrow in the least. Microfinance provide savings service. However, the world remains credit dominated, and therefore the saving ability through an MFI often features a linkage to the customers' inclination to borrow funds from it. Consistent with a 2009 survey of 166 MFIs by Microfinance Information Exchange, all advanced loans whereas just 27\% provided savings facilities. The argument of these who advocate for a wider range of monetary services is that a far better balance should be established (Gujarati, 2004).

H2: Saving Service has significant and positive effect on micro and small enterprises growth.

3.3.3 Training Service

Business management knowledge is vital ingredient to a firm's growth (Macpherson \& Holt, 2007). Business training is critical for enhancing productivity and improving quality of business. It also positively influences the employees' efficiency, effectiveness and motivation (Thassanabanjong et al., 2009). The MSE owner significantly influences the strategies, tactics, operations and decision-making process across the firm. As a consequence, deciding process tends to be centralized round the owner. This MSE characteristic of centralized decision-making means the business-owner personality, skills, responsibilities; attitude and behavior will have a big impact on business strategy (Levy and Powel, 2005). In order to deal with the varied inadequacies that MSE face, one among the solutions that MFIs offers is business management training. Consistent with (Armyx, 2005), it is commonly acknowledged that MSEs are faced by unique challenges that affect their profitability, viability 
and growth thereby diminishing their capacity to effectively contribute to sustainable development. Wanjohi (2007) mentioned that key amongst these challenges is insufficient business management training and knowledge. Consistent with Mugure (2008) some learning institutions have attempted to integrate business management training for MSEs in their programs. However, there is limited knowledge about how MFIs are imparting business management skills among MSE and therefore the impact on growth and development of MSE. H3: Training has significant and positive effect on micro and small enterprises growth.

\section{Methodology}

Wide range of studies have been conducted to check the role of financial institutions; microfinance on MSE growth. By keeping in view of all these researches this study clarifies and take a look of the relationship between independent (Loan service, saving service and training service) and dependent variables (MSE growth) in Dire Dawa Administration, Ethiopia. The tool which has been used for data collection is an adopted questionnaire from different studies. In order to make research valid non probability sampling has been used in this study and only those respondents have been covered who can give you effective input for analysis. A questionnaire has been designed to check the role of financial institutions on the growth of micro and small enterprises by using five-point Likert scale. The structure of the questionnaire has been organized as, in the initial part of questionnaire demographic information have been placed, in the next part of questionnaire the main items of the variables have been placed in four sections. In section one loan service is measured having 5 items. In section two saving service is measured in 5 items. In section three training service has been placed containing 4 items. In section four MSE growths has been placed containing 5 items. In order to derive results from collected data descriptive statistics and regression analysis have been used.

\section{Research Findings and Discussion}

There are 173 respondents which are selected to take input from them in order to make data analysis. The results of data analysis have covered in eleven tables. In table 2, 3, 4, and 5 descriptive statistics has been reported which indicate that mode or medium central tendency descriptive statistics. The results of correlation analysis have been reported in table 6; indicate that predictors have positive and valid correlations with response variable. In order to make results valid regression analysis has also been applied, and the results of regression analysis have been reported in table no 7, 8, 9, 10, 11 and 12. Saving, loan and training have positive relationship with MSE growth. The p-value shows the significance of relationship. As p-value is less than critical value, so it can be said that the variables chosen for study have significant relationship with response variables except training.

\subsection{Descriptive Statistics of Variables}

The respondents were asked to indicate their views on the services offered by Micro Finance Institution (MFI). Information regarding the services was collected using a five (5) Liker Type data instruments. According to Boone and Boone (2012) mode is applied for analyzing descriptive data. In this analysis mode, frequency and percentage used as the primary focal point for discussions of the findings for this Likert data types. The following tables 2, 3, 4 and 5 summarized data show about saving, loan, training and growth of micro and small enterprises.

5.1.1 Saving Service

Table 2 Saving Services

\begin{tabular}{|l|c|c|}
\hline \multicolumn{1}{|c|}{ Saving Service } & N & MODE \\
\hline My MFI encourages me to make regular savings & 173 & 4 \\
\hline I find it convenient and easy to make deposits into my account & 173 & 4 \\
\hline My MFI does not charge ledger fees on my account & 173 & 4 \\
\hline My savings earn good interest in my MFI & 173 & 2 \\
\hline I make regular deposits into my MFI account & 173 & 4 \\
\hline
\end{tabular}

Source: Analysis data Survey 2020, using SPPS. 23

Key: 1-Strongly Disagree, 2-Disagree, 3-Neutral, 4-Agree, 5-Strongly Agree

Table 2 indicates that the participants agrees $($ Mode $\approx 4)$ that Microfinance saving services motivate regular saving, are convenience and easy to operate, does not charge ledger fees and they make regular deposits. These findings agree with (Brau, J. C., \& Woller, G. M. , 2004) who argued that MFI are easily approachable and their services are friendly to business startups though they surfer from financial stability in the long run. The study also found the respondents were of the contrary opinion (Mode $\approx 2$ ) that MFI accounts generate good interest from their savings. According to (Okibo, B. W. \& Makanga, N. , 2014) MFI are meant to provide cheap credit as opposed to commercial banks. The result above may explain why majority of the respondents prefer commercial banks due to high interests accrued from their savings. 


\subsubsection{Loan Service}

Table 3 Loan Services

\begin{tabular}{|l|c|c|}
\hline \multicolumn{1}{|c|}{ Loan Service } & N & MODE \\
\hline Getting a business loan from microfinance does not involved lengthy procedure & 173 & 4 \\
\hline The business loan application process is easy to understand and follow & 173 & 2 \\
\hline Loan applied for from microfinance institution are always granted & 173 & 4 \\
\hline Small loans to meet temporary business shortfalls are promptly granted & 173 & 4 \\
\hline Loan money has helped in making my business grow & 173 & 4 \\
\hline
\end{tabular}

Source: Analysis data Survey 2020, using SPPS.23

Key: 1-Strongly Disagree, 2-Disagree, 3-Neutral, 4-Agree, 5-Strongly Agree

In Table 3 above shows that the respondents agrees (Mode $\approx 4$ ) that MFI have a short process of getting loans, but the application process is easy not to understand and follow (Mode $\approx 2$ ). Small business owners and managers are discouraged to apply for a loan from a financial institution because of administrative frustrations involved in the loan application procedures (Cole, R., \& Sokolyk, T., 2016). The statistics also shows that MFI loans are always granted, small emergency loans are promptly grated and loans grated have helped to MSE business. These observations confirm that MFI will continue to play its rightful role of providing cheap and readily available credit to upcoming MSEs While MFI Should improve loan application process. It is similar to (Abiola Babaide, 2012) found that in his study $95.6 \%$ of the total respondents believe that the contribution of MFIs loan to the growth of SMEs is very high.

5.1.3 Training Service

Table 4 Training Services

\begin{tabular}{|c|c|c|}
\hline Training Service & $\mathbf{N}$ & MODE \\
\hline $\begin{array}{l}\text { Microfinance institutions aggressively give information of their services which are beneficial to } \\
\text { micro and small businesses }\end{array}$ & 173 & 4 \\
\hline $\begin{array}{l}\text { Microfinance institutions trains on how to effectively communicate with customers and has } \\
\text { helped me to retain customers }\end{array}$ & 173 & 2 \\
\hline $\begin{array}{l}\text { Training by microfinance institutions has enabled me to maintain a record of my business } \\
\text { transactions }\end{array}$ & 173 & 2 \\
\hline Microfinance institutions has trained me on how to utilize the loan money & 173 & 2 \\
\hline
\end{tabular}

Source: Analysis data Survey 2020, using SPPS.23

Key: 1-Strongly Disagree, 2-Disagree, 3-Neutral, 4-Agree, 5-Strongly Agree

Table 4 also indicates that the respondents agree (Mode $\approx 4$ ) that MFI aggressively market on the benefits their services to MSE. The study found that the respondents disagreed (Mode $\approx 2$ ) that MFI provide training on record keeping, on how to communicate with customers and how to utilize loans granted. The above revelations are in line with the report by (Ernst \& Young Global Limited, 2014) which found that MFIs lack transparency on their documentation on finance and customer information. In (Alebachew Goshim Azeref \& Yohanes Tefera Gelagil, 2018) the result showed that the contribution of financial institutions especially banks and MFIs to the growth of SMEs in providing continuous training and supervision were very poor. Similarly supported by (Cooper, 2012) established that Microfinance Institutions offer minimal training to SMEs. In the framework, the growth of MSE was the dependent variable and it was indicated by sale, profit, capital, market and financial asset.

5.1.4 Growth of Micro and Small Enterprise

Table 5 MSE Growth

\begin{tabular}{|c|c|c|c|c|c|c|c|c|c|c|}
\hline \multirow[t]{2}{*}{ Level } & \multicolumn{2}{|c|}{ Sales revenues } & \multicolumn{2}{|c|}{ Profitability } & \multicolumn{2}{|c|}{ Physical assets } & \multicolumn{2}{|c|}{ Financial assets } & \multicolumn{2}{|c|}{ Markets coverage } \\
\hline & $\mathbf{F}$ & $\%$ & $\mathbf{F}$ & $\%$ & $\mathbf{F}$ & $\%$ & $\mathbf{F}$ & $\%$ & $\mathbf{F}$ & $\%$ \\
\hline More decreased & 34 & 19.7 & 24 & 13.9 & 26 & 15.0 & 39 & 22.5 & 18 & 10.4 \\
\hline Slight decreased & 28 & 16.2 & 30 & 17.3 & 26 & 15.0 & 29 & 16.8 & 47 & 27.2 \\
\hline Stable & 45 & 26.0 & 49 & 28.3 & 31 & 17.9 & 30 & 17.3 & 61 & 35.3 \\
\hline Slight increased & 51 & 29.5 & 59 & 34.1 & 65 & 37.6 & 71 & 41.0 & 45 & 26.0 \\
\hline More increased & 15 & 8.7 & 11 & 6.4 & 25 & 14.5 & 4 & 2.3 & 2 & 1.2 \\
\hline Total & 173 & 100 & 173 & 100 & 173 & 100 & 173 & 100 & 173 & 100 \\
\hline
\end{tabular}

Source: Analysis data Survey 2020, using SPPS.23

This study assessed the indicators and presented in Table 5. Results from the study indicated that the majority of the respondents showed that there were positive changes in sales revenues, profitability, physical asset, financial asset and market coverage this means there was improvement of business financial performance. According (Muiruri, 2014) in the study demonstrated that MFIs offer services to customers (MSEs) had 
contributed growth which has been rapid over the years and the businesses that received MFI services reported growth in sale, revenue and number of employees employed.

\subsection{Inferential Statistics}

5.2.1 Correlation Result

Table 6 Correlation Result

\begin{tabular}{|l|l|r|}
\hline \multirow{3}{*}{ MSE Growth } & Pearson Correlation & \multicolumn{1}{|c|}{ MSE Growth } \\
\cline { 2 - 3 } & Sig. (2-tailed) & 173 \\
\cline { 2 - 3 } Saving Service & $\mathrm{N}$ & $.378^{* *}$ \\
\hline \multirow{3}{*}{ Training } & Pearson Correlation & .000 \\
\cline { 2 - 3 } & Sig. (2-tailed) & 173 \\
\cline { 2 - 3 } & $\mathrm{N}$ & $.382^{* * *}$ \\
\hline \multirow{5}{*}{ Loan Service } & Pearson Correlation & .000 \\
\cline { 2 - 3 } & Sig. (2-tailed) & 173 \\
\cline { 2 - 3 } & $\mathrm{N}$ & $.738^{* * *}$ \\
\hline & Pearson Correlation & .000 \\
\cline { 2 - 3 } & Sig. (2-tailed) & 173 \\
\cline { 2 - 3 } & $\mathrm{N}$ & \\
\hline
\end{tabular}

**. Correlation is significant at the 0.01 level (2-tailed). *. Correlation is significant at the 0.05 level (2-tailed). Source: Correlation result output 2020, using SPSS

This study employed correlation analysis, which investigates the strength of the relationships between the studied variables. According to Table 6, there were positive relationship between independent variables (training, loan and saving service) and dependent variable (Micro and Small enterprise growth). The highest correlation is between MSE growth and Loan service $(\mathrm{r}=0.738)$, in between Training and MSE growth $(\mathrm{r}=0.382)$, and correlation in between Saving service and MSE growth $(\mathrm{r}=0.378)$. In general, factors towards loan, training and saving service had positive correlation to MSE growth.

5.2.2 Regression Result

In order to make the data ready for analysis and to get reliable results from the research, the model stated previously was tested for multiple linear regression model assumptions.

Table 7 Heteroskedasticity Test: Glejser Test

\begin{tabular}{|l|r|r|r|r|r|}
\hline \multirow{2}{*}{ Model } & \multicolumn{2}{|c|}{ Unstandardized Coefficients } & Standardized Coefficients & \multirow{2}{*}{$\mathrm{t}$} & \multirow{2}{*}{ Sig. } \\
\cline { 2 - 5 } & \multicolumn{1}{|c|}{$\mathrm{B}$} & Std. Error & Beta & \\
\hline 1 (Constant) & .352 & .103 & 3.413 & .001 \\
Saving Service & -.046 & .026 & -.145 & -1.786 \\
Training & .008 & .028 & .076 \\
Loan Service & .010 & .026 & .267 & .790 \\
& & .036 & .396 & .693 \\
\hline
\end{tabular}

a. Dependent Variable: MSE GROWTH

Source: Analysis of Survey data 2020, using SPSS 23

Heteroskedasticity: To test for the absence of heteroskedasticity, Glejser Test was used in this study. If the pvalue is very small, less than 0.05 , it is an indicator for the presence of heteroskedasticity (Gujarati, 2004). Since the p-values are $0.076,0.790$ and 0.693 in Table 7 , which shows that greater than 0.05 it is a clear indicator that there is no evidence for the presence of heteroskedasticity. 
Table 8 Correlation matrix between explanatory variables

Correlations

\begin{tabular}{|c|c|c|c|c|}
\hline & & Saving Service & Training & Loan Service \\
\hline \multirow{3}{*}{ Saving Service } & Pearson Correlation & 1 & $.157^{*}$ & $.343^{* *}$ \\
\hline & Sig. (2-tailed) & & .039 & .000 \\
\hline & $\mathrm{N}$ & 173 & 173 & 173 \\
\hline \multirow{3}{*}{ Training } & Pearson Correlation & $.157^{*}$ & 1 & $.472^{* *}$ \\
\hline & Sig. (2-tailed) & .039 & & .000 \\
\hline & $\mathrm{N}$ & 173 & 173 & 173 \\
\hline \multirow{3}{*}{ Loan Service } & Pearson Correlation & $.343^{\text {*** }}$ & $.472^{\text {*** }}$ & 1 \\
\hline & Sig. (2-tailed) & .000 & .000 & \\
\hline & $\mathrm{N}$ & 173 & 173 & 173 \\
\hline
\end{tabular}

*. Correlation is significant at the 0.05 level (2-tailed).

**. Correlation is significant at the 0.01 level (2-tailed).

Source: Analysis of Survey data 2020, using SPSS

Multicollinearity Test: This study uses high correlation coefficients method to detect the existence of multicollinearity. According to (Joseph and Rosemary, 2003) if the correlation coefficient is higher than 0.8 , it is considered as the model consists of serious multicollinearity problem. Table 8 showed that the highest correlation of 0.343 which is between loan service and saving service. Thus, it can be concluded that all the variables in the study have low correlation power as a result there is no multicollinearity problem in the explanatory variables.

Table 9 Tolerance and VIF result to test Collinearity

\begin{tabular}{|c|c|c|c|}
\hline \multirow{2}{*}{\multicolumn{2}{|c|}{ Model }} & \multicolumn{2}{|c|}{ Collinearity Statistics } \\
\hline & & Tolerance & VIF \\
\hline \multirow[t]{4}{*}{1} & (Constant) & & \\
\hline & Saving Service & .882 & 1.133 \\
\hline & Training & .777 & 1.286 \\
\hline & Loan Service & .703 & 1.422 \\
\hline
\end{tabular}

Source: Analysis of Survey data 2020, using SPSS

Collinearity: The results are presented in the table 9. Two values are given: Tolerance and VIF. Each of the variables had a tolerance value of more than 0.10 and a variance inflation factor (VIF) of less than ten. The finding indicated that no serious multicollinearity problem (Ooiet al., 2006).

Normal P-P Plot of Regression Standardized Residual

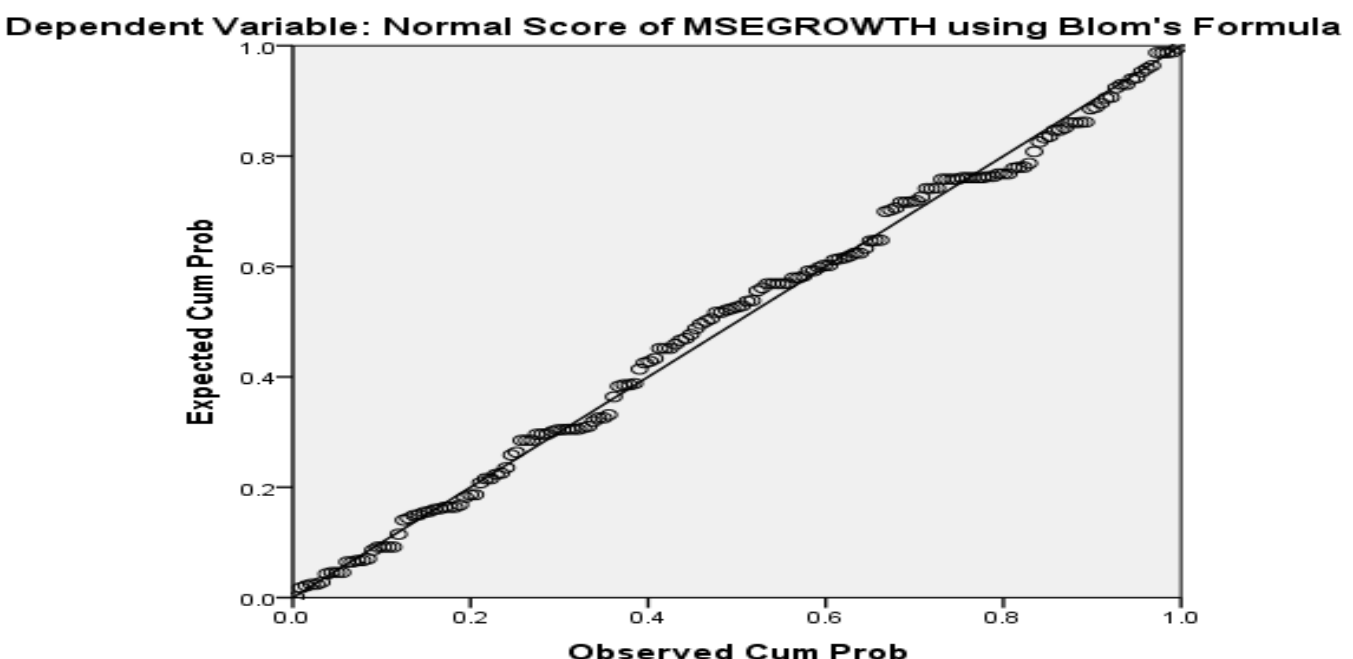

Figure 3 Normal P -P Plot 


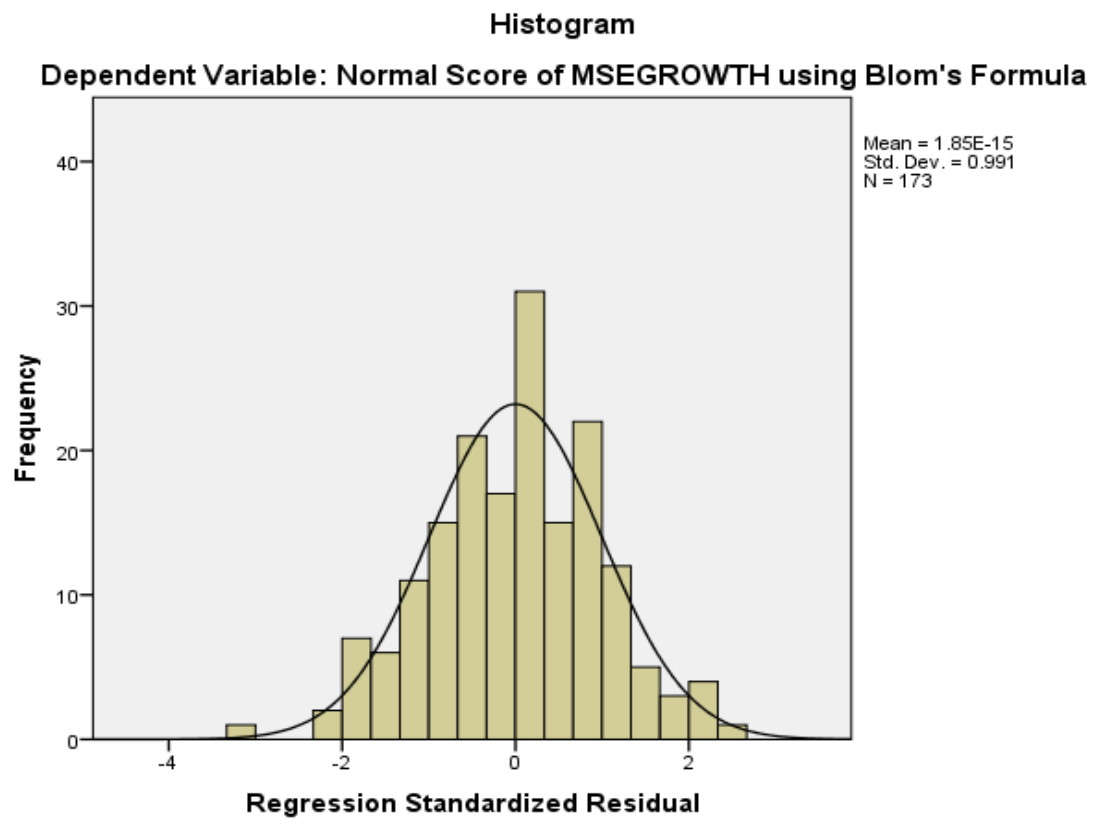

\section{Figure 4 Histogram}

Normality: Ghozali (2006) stated that the normality can be seen on the data distribution when the curve does not pass through either the left or the right. As depicted in Figure 2 and 3, it shows that the data output is normally distributed.

Regression Result and Hypothesis Test

In this study multiple regression analysis was employed to examine the factors towards Loan Service, Saving Service and Training of MSE on the micro and small enterprise growth. Table 10,11,12 presents the results of multiple regressions analysis.

Table 10 Model Summary

Model Summary

\begin{tabular}{|c|r|r|r|r|}
\hline Model & R & R Square & \multicolumn{1}{|c|}{$\begin{array}{c}\text { Adjusted R } \\
\text { Square }\end{array}$} & $\begin{array}{c}\text { Std. Error of the } \\
\text { Estimate }\end{array}$ \\
\hline 1 & $.751^{\mathrm{a}}$ & .564 & .556 & .32758 \\
\hline
\end{tabular}

a. Predictors: (Constant), Loan Service, Saving Service, Training

b. Dependent Variable: MSE Growth

Source: SPSS Regression results output, 2020

The results obtained in model summary (Table 10) shows that, The adjusted R2 of 0.556 indicates $55.6 \%$ of the variance in micro and small enterprise growth can be predicted by factors towards Loan Service, Saving Service and Training of MSE on micro and small enterprise growth. This means that the dependent variable is strongly explained by independent variables. However, the remaining $44.4 \%$ can be explained by other variables. R-Squared greater than $20 \%$ is still large enough for reliable conclusions for such data (Cameron Trivedi, 2009; Hsiao, 2007, cited in Nyamsogoro, 2010).

\section{Table 11 ANOVA}

\begin{tabular}{|l|r|r|r|r|r|}
\hline Model & \multicolumn{1}{|c|}{ Sum of Squares $^{\mid}$df } & Mean Square & F & \multicolumn{1}{c|}{ Sig. } \\
\hline $1 \quad$ Regression & 23.468 & 3 & 7.823 & 72.901 & $.000^{b}$ \\
Residual & 18.135 & 169 & .107 & & \\
Total & 41.603 & 172 & & & \\
\hline
\end{tabular}

a. Dependent Variable: MSE Growth

b. Predictors: (Constant), Loan Service, Saving Service, Training

\section{Source: SPSS Regression results output, 2020}

From the ANOVA Table 11 Show that accepting at least one of the factors towards Loan Service, Saving Service and Training of MSE had significant role on micro and small enterprises growth, since the p-value for FStatistics (0.000). 
Table 12 Beta coefficient of regression result

\begin{tabular}{|c|c|c|c|c|c|c|c|}
\hline \multicolumn{8}{|c|}{ Coefficients $^{\mathrm{a}}$} \\
\hline \multirow{2}{*}{ Model } & \multicolumn{2}{|c|}{ Unstandardized Coefficients } & \multirow{2}{*}{\begin{tabular}{|c|} 
Standardized Coefficients \\
Beta
\end{tabular}} & \multirow{2}{*}{$\mathrm{t}$} & \multirow{2}{*}{ Sig. } & \multicolumn{2}{|c|}{ Collinearity Statistics } \\
\hline & $\mathrm{B}$ & Std. Error & & & & Tolerance & VIF \\
\hline 1 (Constant) & 1.066 & .174 & & 6.136 & .000 & & \\
\hline Saving Service & .113 & .043 & .141 & 2.613 & .010 & .882 & 1.133 \\
\hline Training & .036 & .047 & .044 & .765 & .446 & .777 & 1.286 \\
\hline Loan Service & .483 & .044 & .669 & 11.049 & .000 & .703 & 1.422 \\
\hline
\end{tabular}

a. Dependent Variable: MSE Growth

\section{Regression results output 2020, Using SPSS}

Based on the Coefficient Table 12, Saving Service had a positive and significant effect on micro and small enterprises growth with a beta value $($ Beta $=0.113)$, at 95\% confidence level $(\mathrm{p}<0.05)$. Loan Service had a positive and significant effect on micro and small enterprise growth with a beta value (Beta $=0.483$ ), at $95 \%$ confidence level $(\mathrm{p}<0.05)$. Training of MSE had a positive and insignificant effect on micro and small enterprise growth with a beta value $($ Beta $=0.036)$, at $95 \%$ confidence level $(\mathrm{p}>0.05)$. Therefore, the researcher does accept first and second hypothesis and reject the third hypothesis.

\subsection{Discussion}

5.3.1 Effect of Saving Services from Financial Institution; MFI on the Growth of MSE.

This finding is consistent with other studies Saving Service had as study of (Hamisi Madole, 2013) which agree that most of MSE was reason to saving of money were initial capital, guaranty of borrowers caused by investment return of borrowed money and it has direct effect on the growth of MSE. The findings of this study regarding MFIs saving services on the growth of MSE agrees with those of (Kisaka, S. E. \& Mwewa, N. M., 2014) who found that micro-credit and micro-savings contribute positively to MSE growth and performance. Also Ishengoma and Kappel (2011) established that access to safe and flexible savings services can play a critical role in poor people's strategies for minimizing risks, mitigating income fluctuations, facing unexpected expenditures and emergencies which have helped the MSE to grow. As it is seen from the regression result, saving account from Banks and or MFIs have a significant positive effect on the growth of SMEs.

The lack of good interest from their savings may be the reason the MSE operators prefer to save with commercial banks which offer friendly interests against their savings. The principle of MFIs operations is that the customer must save certain amount of money for one to qualify for a loan. This sometimes keeps off well established MSE from seeking loans from MFI since they can get a loan from banks using their assets together with strength of the account transaction history.

5.3.2 Effect of Loan Services from Financial Institution; MFI on the Growth of MSE.

The findings found the MFI loan services have contributed positively on the growth of MSE. This observation is in agreement with the findings of (Gumel, 2017) and (Kepha Momany \& Osoro Jomo, 2013) who in a study found that MFI loan had a positive of relationship between access to financial institutions loans by small businesses and their growth.

This regression result is also consistent with (Momba, 2013), Gosa, (2014), (Wolday Amha, 2000), Albert.N, (2013) and (Makokha, 2006), which agree that on microfinance credit has played an important effect provides improving the growth of MSE and have positive effect on the asset of the borrowers due to either borrowed money itself or increase in the asset of borrowers caused by investment return of borrowed money.

5.3.3 Effect of Training Services from Financial Institution; MFI on the Growth of MSE.

The study findings above paint a gloomy picture on the MFIs training services. Kisaka and Mwewa (2014) noted that MFI saving services have positively influenced to the growth and performance MSE in Kenya. However, the same authors (Kisaka, S. E. \& Mwewa, N. M., 2014) argued that the training conducted by MFI does not address the material needs of MSE which have led to many MSE especially the mature and well established one to shun MFI services. Although training associates with SMEs growth positively, it is insignificant based on $t$ and $p$ values (Alebachew Goshim Azeref \& Yohanes Tefera Gelagil, 2018). Quansah Ph., Amankwah E and Aikins El argue that training of MSE significant effect on the growth of MSE. Because of training of MSE has play critical effect to improved financial states of MSE (Quansah Ph., Amankwah E and Aikins El,, 2012).

Training on what the MFI can offer help to disseminate information that attract customers and in so doing increase confidence. Lack of proper training programmes leads to information asymmetry which leads to lack confidence and results in low saving with MFIs. The MFIs need to conduct a training needs assessment in order to establish what kind training is suitable for MSE. 


\section{Conclusion}

The objective of this research was to assess the role of financial institutions on the growth of micro and small enterprises in Dire Dawa town. The study examines the statistical significance between financial institution services on the growth of micro and small enterprises. It can be concluded from this research that financial institution saving and loan services have done well in influencing positive and significant growth of MSE while the training services have not. The researcher concluded that the role of financial institution toward MSE growth is a vital important. It was concluded that the nature of the structure of most MSE in Dire Dawa makes credit financing one of the most useful ways for start - up firms and business expansion and it had improving mobilization of saving very helpful. Moreover, majority of enterprises agreed on have profit and sales revenue after being used in financial institution service, So that it shows a significant relationship between financial institution services and MSE growth in Dire Dawa Administration. Although researcher concluded that the major problem faced by enterprises in taking loans from financial institution was long process of loan, high interest rate, challenges of providing favorable services like proper training, variety of saving products and inadequate amount of loans. Therefore, the MFI should look for ways of addressing these shortcomings.

From the study the following recommendations are provided to sustainably improve the development and growth of Micro and Small Enterprises.

1) Access to finance was one of the crucial factors that determine the growth of MSE. Therefore, the Dire Dawa city government bodies should provide affordable alternative sources of finance for MSE. This can be done by communicating with the banks and other credit institutions to revise their requirements.

2) Urban Food security and Job creation bureau and microfinance institution should take actions to reduce bureaucratic procedures, be made available to the MSE at reduced reasonable interest rate, provide variety of saving products and adequate amount of loans will benefit MSE to a greater degree of growth.

3) The study found that the training conducted by MFI does not address the material needs of MSE. So creating link between sectors, such as micro finance, public technic college providing continuous training based on the growth level of the sectors, experience sharing with other sectors within Dire Dawa and other cities is crucial.

\section{References}

Abdulmelike, A., Bese (phd), S., \& Sime, G. (2018). Challenges and Opportunities of MSEs in Ethiopia: A Review paper. Journal of Economics and Sustainable Development, 9(19), 68-74.

Abiola Babaide. (2012). Effects of Microfinance on Micro and Small Enterprises (MSEs) Growth in Nigeria. Asian Economic and Financial Review, 2(3), 463-477.

Alebachew Goshim Azeref, \& Yohanes Tefera Gelagil. (2018). Role of Financial Institution on the Growth of Small and Medium Enterprises:-The Case in North Shewa Zone, Amhara Region, Ethiopia. Journal of Investment and Management, 7(5), 143-150.

Arjona Spahiu, \& Ana Kapaj. (2015). Small and Medium Enterprises Environment - Case of Albania.

Brau, J. C., , \& Woller, G. M. . (2004). Microfinance: A Comprehensive Review of the Existing Literature. The Journal of Entrepreneurial Finance, 9(1), 1-27.

Carl Liedholm. (2001). Small Firm Dynamics: Evidence from Africa and Latin America, World Bank Paper.

Cole, R., , \& Sokolyk, T. (2016). Who needs credit and who gets credit? Evidence from the surveys of small business finances. Journal of Financial Stability, 24(691), 40-60.

Cook, P. and F. Nixon. (2000). Finance and Small and Medium-Sized Enterprise Development. IDPM, University of Manchester. Finance and Development Research Programme Working Paper Series, 14.

Cooper, J. N. (2012). The impact of microfinance services on the growth of small and medium enterprises in Kenya (Doctoral dissertation, University of Nairobi, Kenya).

Diagne, A. , \& M. Zeller. (2001). Access to credit and its impact in Malawi. Research report. International Food Policy Research Institute (IFRI), Washington D.C., USA.

Ernst, \& Young Global Limited. (2014). Challenges in microfinance: An EY perspective.

Gelfeto Gelassa Titta, Dr B. V., , \& Prasada Rao. (2013). Assessing the Contribution of Microfinance Institution Services to Small Scale Enterprises Operation: A Case Study of Omo MFIs, Hawassa City, Ethiopia.

Green, C. J., P. Kimuyu , \& V. Murinde. (2002). "How do Small Firms in Developing Countries Raise Capital? Evidence from a Large-Scale Survey of Kenyan Micro and Small Scale Enterprises". Centre for International,Financial and Economics Research, Department of Economics, Loughborough University, 2(6).

Gujarati. (2004). Sustainable Banking with the Poor: Micro finance hand Book.

Gumel, B. I. (2017). Critical challenges facing small business enterprises in Nigeria: A literature review. International Journal of Scientific and Engineering Research, 8(8), 796-808.

Hamisi Madole . (2013). The impact of microfinance credit on the growth of MSEs in Tanzania' a case study of national microfinance bank- morogoro.

Heidhues, F. (1995). Rural Finance Markets-An Important Tool to Fight Poverty. Quarterly Journal of 
International Agriculture, 34(2), 105-108.

Hill, T. (1987). Small business production or operations management. London: Macmillan Education Ltd.

ILO. (2003). Ethiopian Women Entrepreneurs: Going for Growth. ILO Sub-regional Office, Addis Ababa and Ministry of Trade and Industry, Women's Affairs Department in Association with SEED, ILO, and Geneva, Department in Association with SEED, ILO, and Geneva.

Ishengoma, E. K., \& Kappel, R. (2011). Business environment and growth potential of micro and small manufacturing enterprises in Uganda . African Development Review, 23(3), 352-365.

Kepha Momany, \& Osoro Jomo. (2013). The role of Micro Finance Institution on the growth of SMEs in Kenya; a case study of MFIs in Kisi Town. IOSR Journal of Humanities and social science, 83-93.

Kessy, S., \& Temu, S.S. (2010). The Impact of Training on Performance of Micro and Small Enterprises Served by Microfinance Institutions in Tanzania. Research Journal of Business Management, 4, 103-111.

Kisaka, S. E., \& Mwewa, N. M. (2014). Effects of Micro-credit, Micro-savings and Training on the Growth of Small and Medium Enterprises in Machakos County in Kenya. Research Journal of Finance and Accounting, 5(7), 43-49.

Makokha. (2006). Access to Financial Services in Brazil, the World Bank: Washington D.C.

mdar, D., and A. Mazaheri . (2003). The African manufacturing firm, an analysis based on firm surveys in seven countries in sub-Saharan Africa. London: Routledge.

Momba. (2013). Credit for the alleviation of rural poverty: The Grameen Bank in Bangladesh. Bangladesh. IFPRI Research Report.

MSE Strategy. (2011). Micro and Small Enterprise Development Strategy, provision framework and methods of Implementation. Addis Ababa, Ethiopia: Government of the Federal Democratic Republic of Ethiopia.

Muiruri, P. M. (2014). The Role of Micro-Finance Institutions to the Growth of Micro and Small Enterprises (MSE) in Thika, Kenya (Empirical Review of Non- Financial Factors). International Journal of Academic Research in Accounting, Finance and Management Sciences, 4(4), 249-262.

Navajas, S., Schreiner, M., Meyer, R.L, Gonzalez-Vega, C., \& Rodrigez-Mesa, J. (2000). Microcredit and the Poorest of the Poor: Theory and Evidence from Bolivia. World Development.

Nigussie, D. W. (2012). Role of Financial Institutions in the Growth of Small and Medium. .

Okibo, B. W., \& Makanga, N. . (2014). Okibo, B. W., \& Makanga, N. (2014). Effects of micro finance institutions on poverty reduction in Kenya. International Journal of the Current Research and Academic Review, 76-95.

Quansah Ph., Amankwah E and Aikins El,. (2012). Influence of Micro Finance and Small Loan Centre (MASLOC) on the Development of Small Scale Enterprises in the WA Municipality.

Quaye, I., \& Sarbah , A. (2014). Assessing Alternative Sources of Financing for Small \& Medium Scale Enterprises in Ghana: A Case Study of Savings and Loans Companies in the Greater Accra Region of Ghana. International Journal of Advancements in Research \& Technology, 3(7), 123-136.

Robinson, M. (2003). The microfinance revolution: Sustainable finance for the poor. Washington D.C: World Bank.(1).

Thalassinos, I.E., Pintea, M., \& Raţiu, I.P. . (2015). The Recent Financial Crisis and Its Impact on he Performance Indicators of Selected Countries during the Crisis Period: A Reply. International Journal of Economics and Business Administration, 3(1), 3-20.

United Nations Capital Development Fund (UNCDF). (2004). Results-oriented annual report of the United Nations Capital Development Fund. New York.

Wanambisi, A. N. (2013). International Journal of Academic Research in Business and Social Sciences.

Weinzimmer, e. a. (1998). Wei1998, Measuring organizational growth: Issues, consequences and guidelines. Journal of Management, 24(2), 235-262.

Wolday Amha. (2000). Review of Microfinance Industry in Ethiopia: Regulatory frameworks and performance, Occasional paper No.2.

Zeller, M. (1993). Participation of rural households in informal and formal credit markets in Madagascar. Washington, D.C.: IFPRI.

\section{Author}

Abel Zegeye W/Gebriel, Master of Business Administration (MBA), Instructor Business and Accounting Department, Ethio-Italy Polytechnic College Dire Dawa Administration, Ethiopia 